\title{
Oxygen Consumption in South African Sauvignon Blanc Wines: Role of Glutathione, Sulphur Dioxide and Certain Phenolics
}

\author{
D. Fracassetti ${ }^{1}$, C. Coetzee ${ }^{2}$, A. Vanzo $^{3}$, D. Ballabio ${ }^{4}$, W.J. du Toit ${ }^{*}$ \\ (1) Department of Food, Environmental and Nutritional Sciences, Università degli Studi di Milano, Via G. Celoria 2, 20133 \\ Milano, Italy \\ (2) Department of Viticulture and Oenology, Stellenbosch University, Victoria Street, Stellenbosch, South Africa \\ (3) Central Laboratory, Agricultural Institute of Slovenia, Hacquetova 17, 1000 Ljubljana, Slovenia \\ (4) Milano Chemometrics and QSAR Research Group, Department of Environmental Sciences, University of Milano-Bicocca, \\ P.za della Scienza, 1, 20126 Milano, Italy
}

Submitted for publication: October 2012

Accepted for publication: May 2013

Key words: Glutathione, sulphur dioxide, oxygen consumption, white wine, phenols

\begin{abstract}
The aim of this research was to investigate the interaction between sulphur dioxide, glutathione (GSH) and certain phenols in the presence of oxygen in a synthetic wine and in clarified Sauvignon blanc wine. In this study, the clarified wine, from which most of the phenols had been removed, was compared to synthetic wine solution, with both mediums being enriched with caffeic acid to investigate the effect of different levels of sulphur dioxide and GSH on oxygen consumption. Moreover, thirteen young South African Sauvignon blanc wines with different levels of sulphur dioxide were oxygenated, and the oxygen consumption and phenolic and colour changes were monitored over time. The results show that oxygen consumption was influenced greatly by the presence of sulphur dioxide and, to a lesser extent, by the presence of GSH, with both compounds decreasing during the course of the experiment. During oxidation, an increase was observed in glutathionyl caffeic acid, as well as in oxidised glutathione (GSSG); however, this did not coincide with the percentage decrease in GSH. Oxidation further led to an increase in absorbance measurements at 420 and $440 \mathrm{~nm}$ (yellow-orange colour), which were reduced by the presence of $\mathrm{SO}_{2}$. A large variation was also observed in the oxygen consumption of the young wines, with this rate increasing with an increase in $\mathrm{SO}_{2}$ concentration. Positive correlations were also observed between oxygen, $\mathrm{SO}_{2}, \mathrm{GSH}$ and $C u$ concentrations, which were again negatively correlated with absorbance at 420 and $440 \mathrm{~nm}$ and GSSG concentrations.
\end{abstract}

\section{INTRODUCTION}

Contact with oxygen can occur during the production and ageing of white wine, potentially leading to oxidation. In wine, oxidation is a chemical reaction involving certain phenols that can lead to the browning of the wine, as well as an unwanted decrease in aroma and flavour (Simpson, 1982; Fabios et al., 2000; Labrouche et al., 2005; Roussis \& Sergianitis, 2008). This oxidation arises due to the reaction between oxygen and naturally occurring antioxidants, such as phenols and glutathione (GSH), and those added or formed by yeast, such as sulphur dioxide $\left(\mathrm{SO}_{2}\right)$. Most often, the reaction is a complex interaction between these compounds. The addition of $\mathrm{SO}_{2}$ is a winemaking practice usually carried out to prevent antimicrobial spoilage and chemical oxidation, thereby preventing certain undesirable sensorial changes from taking place in the wine. $\mathrm{SO}_{2}$ can remove hydrogen peroxide formed by the oxidation of phenols, and has the ability to reduce oxidised $o$-quinones back to a reduced form, thereby accelerating the consumption of oxygen in wine (Danilewicz et al., 2008). The interaction between $\mathrm{SO}_{2}$ and oxygen is quite complex, and metals such as iron and copper have a strong effect on the oxidative mechanisms involving $\mathrm{SO}_{2}$, oxygen and polyphenols, either in wine (Danilewicz et al., 2008) or in a synthetic wine medium (Danilewicz, 2007). However, the use of $\mathrm{SO}_{2}$ should be limited because of its allergenic properties and health implications, such as contributing to asthma, and this necessitates a better understanding of its role in oxygen consumption and the possibility of substituting it with other antioxidant compounds.

Besides through the use of $\mathrm{SO}_{2}$, the protection of wine against oxidation can also be carried out by naturally occurring wine constituents, such as GSH. GSH can reduce the $o$-quinones derived from the enzymatic oxidation of the

*Corresponding author: E-mail: wdutoit@sun.ac.za

Aknowledgements:The authors would like to thank the NRF, Winetech and THRIP for financial support, and the cellars for donating the wine. This study was co-financed by the post-doctoral fellowship "Dote Ricerca": FSE, Regione Lombardia 
tartaric acid esters of hydroxycinnamic acids (such as tartaric ester of caffeic acid, i.e. trans-caftaric acid) in must and prevent their polymerisation and subsequent wine browning (Salgues et al., 1986). In this way, 2-S-glutathionyl caftaric acid, also known as grape reaction product (GRP), is formed (Singleton et al., 1984). GSH has also been shown to exert a protective effect on the volatile thiols of wine, acting as a competitor to the reaction with the $o$-quinones (Lavigne \& Dubourdieu, 2004). It can also protect some volatiles during wine storage in the bottle (Papadopoulou \& Roussis, 2008; Ugliano et al., 2011), especially if caffeic acid is present in the wine at certain levels (15 to $30 \mathrm{mg} / \mathrm{L}$ ) (Roussis et al., 2007; Roussis \& Sergianitis, 2008). GSH could also decrease the formation of sotolon (3-hydroxy-4,5-dimethylfuran-2 $(5 \mathrm{H})$ one), a compound responsible for the aroma of an atypically aged wine (Lavigne \& Dubourdieu, 2004). Moreover, it can have a positive effect on white wine colour, preventing coloration during ageing (Lavigne \& Dubourdieu, 2004; Hosry et al., 2009).

Some studies in the past have investigated the interaction of GSH, oxygen and certain phenolic compounds in must, but little attention has been paid to the interaction of these compounds with $\mathrm{SO}_{2}$ in both wine and synthetic wine. Surprisingly little work has been done on controlled oxygen consumption by different white wines, with most work being done where enzymatic or forced oxidation has been applied. The different factors (i.e. phenolic composition, metals, $\mathrm{SO}_{2}$ ) affecting the consumption of oxygen in a variety of white wines are also not well understood (Cilliers \& Singleton, 1989, 1990a, 1990b, 1991; Du Toit, 2006; Danilewicz et al., 2008; Sonni et al., 2011).

Sauvignon blanc is an important white grape cultivar in South Africa, and winemakers often employ very reductive winemaking processes to prevent possible chemical oxidation. This research was carried out in order to better understand the effect of $\mathrm{SO}_{2}$ and $\mathrm{GSH}$ on oxygen consumption in synthetic wine solution and clarified Sauvignon blanc wine (having low phenol content), which was then enriched with caffeic acid. We also investigated 13 different young Sauvignon blanc wines in terms of their ability to consume oxygen, and how $\mathrm{SO}_{2}$ additions affected this. Moreover, this research aimed to correlate the composition of these wines with the rate of oxygen consumption.

\section{MATERIALS AND METHODS \\ Chemicals}

The compounds used were 3-mercaptopropionic acid (3MPA), p-benzoquinone (pBQ), potassium metabisulphite $\left(\mathrm{K}_{2} \mathrm{~S}_{2} \mathrm{O}_{5}\right)$, copper(II) sulphate pentahydrate $\left(\mathrm{CuSO}_{4} .5 \mathrm{H}_{2} \mathrm{O}\right)$, and iron(II) sulphate heptahydrate $\left(\mathrm{FeSO}_{4} \cdot 7 \mathrm{H}_{2} \mathrm{O}\right)$, all purchased from Fluka (Buchs, Switzerland). Reduced glutathione (GSH), oxidised glutathione (GSSG), transcaffeic acid, $p$-coumaric acid, ferulic acid and catechin, HPLC-grade methanol, absolute ethanol and trifluoroacetic acid (TFA) were obtained from Sigma-Aldrich (St. Louis, $\mathrm{MO}$ ), and trans-caftaric acid came from Dalton Chemical Laboratories (Toronto, Canada). Both cis- and trans-caftaric, $p$-coutaric and fertaric acid were extracted from the grapes (Vitis vinifera, cv. Rhine Riesling) and purified as described by Vanzo et al. (2007). Water was obtained from a Milli-Q purification system (Millipore Filter Corp., Bedford, MA).

\section{Clarified and synthetic wine}

A 2010 vintage Sauvignon blanc wine was collected from the producer just after alcoholic fermentation. The wine was then treated with bentonite and active carbon at doses of $0.1 \mathrm{~g} / \mathrm{L}$ and $0.4 \mathrm{~g} / \mathrm{L}$ respectively. This was done in order to remove proteins and phenols from the wine, which will be referred to from here on as clarified wine. The ethanol concentration and the $\mathrm{pH}$ of the clarified wine were $12.2 \pm 0.3 \%$ and 3.5 respectively. The total $\mathrm{SO}_{2}$ content of the clarified wine at this stage was $19.7 \mathrm{mg} / \mathrm{L}$ (free $\mathrm{SO}_{2}$ was $5.5 \mathrm{mg} / \mathrm{L}$ ). An additional $30 \mathrm{mg} / \mathrm{L} \mathrm{SO}_{2}$ was added, using a $2.5 \% \mathrm{SO}_{2}$ stock solution, where required, to achieve a concentration of around $50 \mathrm{mg} / \mathrm{L}$ total $\mathrm{SO}_{2}$. Glutathione and caffeic acid were not detected in the clarified wine, but were added at 67.5 $\mathrm{mg} / \mathrm{L}$ and $39.6 \mathrm{mg} / \mathrm{L}$ respectively, where required. The total phenol content of this wine was found to be $18 \mathrm{mg} / \mathrm{L}$. The iron concentration of the clarified wine was found to be 0.21 $\mathrm{mg} / \mathrm{L}$, and this was increased to $5 \mathrm{mg} / \mathrm{L}$ (using $\mathrm{FeSO}_{4} \cdot 7 \mathrm{H}_{2} \mathrm{O}$ ), whereas the copper concentration was $0.12 \mathrm{mg} / \mathrm{L}$ with no further additions.

The synthetic wine solution consisted of $12 \%$ ethanol, $5.5 \mathrm{~g} / \mathrm{L}$ tartaric acid, and the $\mathrm{pH}$ was adjusted to 3.5. Sulphur dioxide additions were made at two levels, namely $20 \mathrm{mg} / \mathrm{L}$ and $50 \mathrm{mg} / \mathrm{L}$, to be in accordance with the clarified wine. The addition of GSH, caffeic acid (Table 1), iron (5 mg/L) and copper $(0.12 \mathrm{mg} / \mathrm{L})$ (using $\left.\mathrm{CuSO}_{4} .5 \mathrm{H}_{2} \mathrm{O}\right)$ was also done to match the concentrations of the clarified wine. This is in accordance with the concentrations used by Danilewicz (2007) when investigating the oxidation of phenols in a wine medium.

The clarified and synthetic wine were spiked with the required concentration of $\mathrm{SO}_{2}$, left to stand for one hour and then stirred for five minutes. This was done in a $2 \mathrm{~L}$ glass container. Where applicable, the specific additions of GSH and caffeic acid were made. All treatments received iron and copper additions, after which the mixtures were again stirred to reach an oxygen concentration of around 7 $\mathrm{mg} / \mathrm{L}$ measured by a dipping probe (PreSens, Regensburg, Germany). The $100 \mathrm{~mL}$ glass bottles were filled completely, sealed hermitically and stored in a dark room at $37^{\circ} \mathrm{C}$ for 60 days. All treatments were performed in triplicate. Treatments and additions (different combinations of caffeic acid, GSH and $\mathrm{SO}_{2}$ ) are summarised in Table 1 .

The dissolved oxygen concentration in the clarified wine and synthetic wine was monitored two to three times daily for 60 days by using oxygen sensor spots (Pst3; PreSens, Regensburg, Germany). These spots were placed inside the container and in contact with the medium, thereby permitting the measurement without opening the vessel.

Sampling was carried out from different bottles at each sampling point; thus a new bottle from each treatment was opened at each sampling point, analyses performed where after the rest of the sample was discarded.

Sampling for GSH and caffeic acid, and free and total $\mathrm{SO}_{2}$ analyses, took place five times during the 60 -day period. The first sampling took place at the beginning of the trial (day 0 ), after which sampling took place on days 5, 23 and 
TABLE 1

Code and layout of the different treatments.

\begin{tabular}{|c|c|c|c|c|}
\hline \multirow{3}{*}{ Treatment code } & \multirow{3}{*}{ Medium } & \multicolumn{2}{|c|}{ Addition } & \multirow{2}{*}{$\frac{\text { Concentration }}{\text { Total } \mathrm{SO}_{2}}$} \\
\hline & & Caffeic acid & GSH & \\
\hline & & $\mathrm{mg} / \mathrm{L}$ & $\mathrm{mg} / \mathrm{L}$ & $\mathrm{mg} / \mathrm{L}$ \\
\hline $\mathrm{w} /+\mathrm{c} /-\mathrm{G} /$ low $\mathrm{SO}_{2}$ & depleted wine & 39.6 & not added & 17 \\
\hline $\mathrm{w} /+\mathrm{c} /+\mathrm{G} /$ low $\mathrm{SO}_{2}$ & depleted wine & 39.6 & 67.5 & 17 \\
\hline $\mathrm{w} /+\mathrm{c} /-\mathrm{G} /$ high $\mathrm{SO}_{2}$ & depleted wine & 39.6 & not added & 50 \\
\hline $\mathrm{w} /+\mathrm{c} /+\mathrm{G} /$ high $\mathrm{SO}_{2}$ & depleted wine & 39.6 & 67.5 & 50 \\
\hline $\mathrm{w} /-\mathrm{c} /-\mathrm{G} /$ low $\mathrm{SO}_{2}$ & depleted wine & not added & not added & 17 \\
\hline $\mathrm{s} /+\mathrm{c} /-\mathrm{G} /$ low $\mathrm{SO}_{2}$ & synthetic wine & 39.6 & not added & 20 \\
\hline $\mathrm{s} /+\mathrm{c} /+\mathrm{G} /$ low $\mathrm{SO}_{2}$ & synthetic wine & 39.6 & 67.5 & 20 \\
\hline $\mathrm{s} /+\mathrm{c} /-\mathrm{G} /$ high $\mathrm{SO}_{2}$ & synthetic wine & 39.6 & not added & 50 \\
\hline $\mathrm{s} /+\mathrm{c} /+\mathrm{G} /$ high $\mathrm{SO}_{2}$ & synthetic wine & 39.6 & 67.5 & 50 \\
\hline $\mathrm{s} /-\mathrm{c} /-\mathrm{G} /$ low $\mathrm{SO}_{2}$ & synthetic wine & not added & not added & 20 \\
\hline
\end{tabular}

42, and at the end of the trial (day 60). A summary of the analysed compounds is presented in Table 2. Both cis- and trans-caftaric, $p$-coutaric and fertaric acid, together with GRP, glutathionyl-caffeic acid, $p$-coumaric acid, ferulic acid and total hydroxycinnamic acids (HCAs), were quantified on days 0,23 and 60 . GSSG in the clarified and synthetic wine was measured at day 0,23 and 60 for the treatments to which GSH had been added. In the case of the treatments to which no GSH was added, GSSG analysis was performed only on day 0 and 60 for the clarified wine. For the synthetic wine, no GSSG analysis was done for the treatments to which no GSH had been added. For the analyses of copper and iron, samples were drawn and analysed on days 0 and 60. Absorbance measurements at $280 \mathrm{~nm}, 420 \mathrm{~nm}$ and 440 $\mathrm{nm}$ were done at all five stages for both the clarified and the synthetic wine.

\section{Young wines}

Thirteen young 2010 Sauvignon blanc wines were collected from different commercial cellars shortly after alcoholic fermentation and before any $\mathrm{SO}_{2}$ additions had been made by the producers. This was done with minimum exposure to oxygen by flushing the containers with $\mathrm{CO}_{2}$ gas before filling them with wine. The ethanol concentration ranged from $12.3 \%$ to $13 \%$ and the $\mathrm{pH}$ values were between 3.2 and 3.5. Each of the wines was divided into two $1 \mathrm{~L}$ aliquots; one of the aliquots received $30 \mathrm{mg} / \mathrm{L} \mathrm{SO}_{2}$, while the other received no $\mathrm{SO}_{2}$ additions. An hour after the $\mathrm{SO}_{2}$ addition, the wines were stirred for five minutes to ensure oxygen saturation. The wines were then transferred into $100 \mathrm{~mL}$ bottles, sealed hermitically and stored in the dark at $37^{\circ} \mathrm{C}$ for 60 days.

The treatments carried out on each wine were thus as follows:

1) no addition;

2) addition of $30 \mathrm{mg} / \mathrm{L} \mathrm{SO}_{2}$

The dissolved oxygen concentration was monitored two to three times daily using oxygen sensor spots fitted inside each bottle. Wines were analysed at the beginning and at the end of the experiment.
The investigated parameters were: GSH, catechin, caffeic acid, ascorbic acid, GSSG, free and total $\mathrm{SO}_{2}$, cis-caftaric acid, trans-caftaric acid, cis-coutaric acid, trans-coutaric acid, cis-fertaric acid, trans-fertaric acid, p-coumaric acid, ferulic acid, total HCAs, GRP, glutathionyl caffeic acid, copper, iron and various absorbance measurements (wavelengths $280 \mathrm{~nm}, 420 \mathrm{~nm}$ and $440 \mathrm{~nm}$ ).

\section{Quantification of reduced glutathione, caffeic acid and catechin}

The quantification of GSH, caffeic acid and catechin was carried out by ultra-pressure liquid chromatography (UPLC) with fluorescence detector, as described by Fracassetti et al. (2011). Sample preparation required only a short centrifugation (14 $000 \mathrm{rpm}$ for five minutes), after which derivatisation was done using $\mathrm{pBQ}$. The detection limit (LOD), corresponding to a signal-to-noise ratio $(\mathrm{S} / \mathrm{N})$ of 3, was $0.017 \mathrm{mg} / \mathrm{L}$ for $\mathrm{GSH}, 0.014 \mathrm{mg} / \mathrm{L}$ for catechin and $0.0026 \mathrm{mg} / \mathrm{L}$ for caffeic acid. The quantification limit (LOQ, $\mathrm{S} / \mathrm{N}=10$ ) was $0.057 \mathrm{mg} / \mathrm{L}, 0.048 \mathrm{mg} / \mathrm{L}$ and 0.0088 $\mathrm{mg} / \mathrm{L}$ for $\mathrm{GSH}$, catechin and caffeic acid respectively. The repeatability was assessed at three different concentrations for $\mathrm{GSH}$, catechin and caffeic acid. The relative standard deviation (RSD) was calculated $(\mathrm{N}=9)$ as $7.4 \%, 5.7 \%$ and $6.2 \%$ for $\mathrm{GSH}$, catechin and caffeic acid respectively in grape juice, while in white wine the RSD was $4.2 \%, 4.1 \%$ and $3.6 \%$ respectively.

\section{Quantification of sulphur dioxide}

The total and free $\mathrm{SO}_{2}$ was determined by titration as described in the OIV method: OIV-MA-AS323-04B: R2009. The $\mathrm{SO}_{2}$ content was expressed in $\mathrm{mg} / \mathrm{L}$.

\section{Quantification of hydroxycinnamic acids}

The content of cis- and trans-caftaric acid, coutaric acid and fertaric acid, together with GRP, glutathionyl caffeic acid, caffeic, $p$-coumaric, ferulic acid and total HCAs (expressed as caftaric acid equivalents), was determined by high performance liquid chromatography (HPLC) as described by Vanzo et al. (2007). The method was adjusted by injecting 10 $\mu \mathrm{L}$. Total HCAs was calculated by the sum of cis- and trans- 
TABLE 2

Summary of the analyses done on the depleted and synthetic wine.

\begin{tabular}{|c|c|c|c|c|c|}
\hline \multirow{2}{*}{ Compound } & \multicolumn{5}{|c|}{ Sampling time (day) } \\
\hline & 0 & 5 & 23 & 42 & 60 \\
\hline GSH & $\mathrm{X}$ & $\mathrm{X}$ & $\mathrm{X}$ & $\mathrm{X}$ & $\mathrm{X}$ \\
\hline Caffeic acid & $\mathrm{X}$ & $\mathrm{X}$ & $\mathrm{X}$ & $\mathrm{X}$ & $\mathrm{X}$ \\
\hline Free and total $\mathrm{SO}_{2}$ & $\mathrm{X}$ & $\mathrm{X}$ & $\mathrm{X}$ & $\mathrm{X}$ & $\mathrm{X}$ \\
\hline Cis-caftaric acid & $\mathrm{X}$ & & $\mathrm{X}$ & & $\mathrm{X}$ \\
\hline Trans-caftaric acid & $\mathrm{X}$ & & $\mathrm{X}$ & & $\mathrm{X}$ \\
\hline GRP & $\mathrm{X}$ & & $\mathrm{X}$ & & $\mathrm{X}$ \\
\hline Glutathionyl-caffeic acid & $\mathrm{X}$ & & $\mathrm{X}$ & & $\mathrm{X}$ \\
\hline Cis-coutaric acid & $\mathrm{X}$ & & $\mathrm{X}$ & & $\mathrm{X}$ \\
\hline Trans-coutaric acid & $\mathrm{X}$ & & $\mathrm{X}$ & & $\mathrm{X}$ \\
\hline Cis-fertaric acid & $\mathrm{X}$ & & $\mathrm{X}$ & & $\mathrm{X}$ \\
\hline$p$-coumaric acid & $\mathrm{X}$ & & $\mathrm{X}$ & & $\mathrm{X}$ \\
\hline Ferulic acid & $\mathrm{X}$ & & $\mathrm{X}$ & & $\mathrm{X}$ \\
\hline Total HCAs & $\mathrm{X}$ & & $\mathrm{X}$ & & $\mathrm{X}$ \\
\hline GSSG & $\mathrm{X}^{\#}$ & & $\mathrm{X}^{*}$ & & $\mathrm{X}^{\ddagger}$ \\
\hline Copper & $\mathrm{X}$ & & & & $\mathrm{X}$ \\
\hline Iron & $\mathrm{X}$ & & & & $\mathrm{X}$ \\
\hline Absorbance $280 \mathrm{~nm}, 420 \mathrm{~nm}, 440 \mathrm{~nm}$ & $\mathrm{X}$ & $\mathrm{X}$ & $\mathrm{X}$ & $\mathrm{X}$ & $\mathrm{X}$ \\
\hline
\end{tabular}

$\mathrm{X}^{*}$ : only for the treatments to which GSH was added; $\mathrm{X}^{\sharp}$ : for every depleted wine treatment and for synthetic wine solution to which GSH was added

caftaric, coutaric and fertaric acid together with their free forms, i.e. caffeic, $p$-coumaric and ferulic acid. Compounds were identified by their UV/Vis spectra and retention times. Quantification of the compounds was based on peak areas at $\lambda=320 \mathrm{~nm}$ and the respective concentrations in the samples were expressed as trans-caftaric acid equivalents. The calibration curve was constructed by injecting a standard of trans-caftaric acid in the range from 1.05 to $500 \mathrm{mg} / \mathrm{L}$. A linear curve was obtained with a correlation coefficient of 0.99987. The LOD of trans-caftaric acid was $0.05 \mathrm{mg} / \mathrm{L}$, whereas the LOQ was $0.17 \mathrm{mg} / \mathrm{L}$. To assess the repeatability properties of the method, $121 \mathrm{mg} / \mathrm{L}$ of trans-caftaric acid was sequentially injected $(\mathrm{N}=10)$ and the RSD of the concentration was $0.19 \%$.

\section{Quantification of total phenol content}

The total phenol content (expressed as $\mathrm{mg} / \mathrm{L}$ caftaric acid equivalents) was measured by HPLC (peaks integrated at 320 $\mathrm{nm}, 420 \mathrm{~nm}$ and $440 \mathrm{~nm}$ ), based on a method published by Peng et al. (2002). This was only done for the clarified wine samples after treatment with active carbon and bentonite in order to assess the content before the trial.

\section{Quantification of oxidised glutathione}

The quantification of GSSG was conducted by liquid chromatography coupled with mass spectrometry (LCMSMS), as described by Du Toit et al. (2007). Ethanol was removed from the wine sample under reduced pressure at $40^{\circ} \mathrm{C}$ by a rotary evaporator, and the wine sample was redissolved to the initial volume with deionised water. The sample was filtered through a $0.45 \mu \mathrm{m}$ syringe filter prior to the LC-MSMS analysis. The LOD was $0.2 \mathrm{mg} / \mathrm{L}$ and the
LOQ was $0.8 \mathrm{mg} / \mathrm{L}$. The RSD was calculated as $0.4 \%$ in the $40 \mathrm{mg} / \mathrm{L}$ range $(\mathrm{N}=6)$.

\section{Quantification of copper and iron}

The iron and copper concentrations were determined by atomic absorption spectrometry, as described in the OIV method: MA-F-AS322-05-FER for iron and MA-F-AS32206-CUIVRE for copper. Analysis was done by an ISO 9000 -accredited laboratory that does routine wine analyses for the South African wine industry. For the iron analyses, ethanol evaporation was done prior to the analyses.

\section{Quantification of ascorbic acid}

The ascorbic acid concentration was determined by an ISO 9000 -accredited laboratory that does routine wine analyses for the South African wine industry. The method is based on an automated enzymatic procedure using the Enzytec L-ascorbic acid kit of R-BiopharmThermo Fisher (Darmstad, Germany).

\section{Data analyses}

The statistical analysis was performed using STATISTICA 9 software (Statsoft Inc., Tulsa, OK, US). ANOVA, with type of treatment as the dependent factor, was used to evaluate the variations in the analysed compounds. Fisher's least significant difference (LSD) corrections were used for post-hoc analyses. Significant differences were judged on a $5 \%$ significance level $(\mathrm{p}<0.05)$. Data were analysed also by means of principal component analysis (PCA) (Jolliffe, 1986). PCA was carried out using in-house MATLAB modules. The correlation coefficients between dissolved oxygen, $\mathrm{GSH}, \mathrm{SO}_{2}$, caffeic acid, copper and the absorbance 
at $280 \mathrm{~nm}, 420 \mathrm{~nm}$ and 440 and were computed through the Pearson correlation. Calculations were performed in MATLAB 6.5 (Mathworks).

The rate of oxygen consumption was evaluated through the slope of the curve obtained from the dissolved oxygen measurements (expressed in $\mathrm{mg} / \mathrm{L}$ ) for each treatment. Significant differences $(p<0.05)$ among the slopes of the curves were also evaluated.

\section{RESULTS AND DISCUSSION}

\section{Clarified and synthetic wine}

After being treated with active carbon, the clarified Sauvignon blanc wine had a low total phenol content (18 mg/L). This total phenol concentration was considered acceptable for this study, since it was lower than what has been reported in the literature for white wine (Margalit, 1997; Ribéreau-Gayon et al., 2006). No ascorbic acid was detected in the clarified wine, while the free and total $\mathrm{SO}_{2}$ content was $5.5 \mathrm{mg} / \mathrm{L}$ and $19.7 \mathrm{mg} / \mathrm{L}$ respectively. According to the winemaker, no $\mathrm{SO}_{2}$ addition was made after fermentation, and this could indicate some $\mathrm{SO}_{2}$ being produced by the yeast during fermentation (Dott et al., 1976).

Dissolved oxygen concentrations were monitored for all 10 treatments during the 60 -day trial period and can be seen in Fig. 1 (refer to Table 1 for a detailed explanation of the different treatments). The dissolved oxygen concentration for treatment $\mathrm{s} /-\mathrm{c} /-\mathrm{G} /$ low $\mathrm{SO}_{2}$ remained relatively constant during the experiment. The quick oxygen consumption in treatment $\mathrm{w} /-\mathrm{c} /-\mathrm{G} /$ low $\mathrm{SO}_{2}$ suggests that the clarified wine still contained a substantial amount of wine antioxidants, reacting with the oxygen and thus causing a faster depletion of the dissolved oxygen levels when compared to treatment $\mathrm{s} /-\mathrm{c} /-\mathrm{G} /$ low $\mathrm{SO}_{2}$, where no oxygen consumption took place. Surprisingly, there was no significant difference in the rate of oxygen consumption between treatment w/+c/-G/low $\mathrm{SO}_{2}$ and treatment $\mathrm{w} /-\mathrm{c} /-\mathrm{G} /$ low $\mathrm{SO}_{2}(p=0.995)$. It would seem that the presence of caffeic acid had little or no effect on the rate of consumption. It has been shown that the reaction of dissociated caffeic acid and oxygen is slow under wine conditions (Cilliers \& Singleton, 1989, 1991). The presence of tartaric acid could possibly compete for iron and also hinder caffeic acid oxidation (Danilewicz, 2003). When comparing treatments $\mathrm{w} /+\mathrm{c} /-\mathrm{G} / \mathrm{low} \mathrm{SO}_{2}$, w/+c/+G/low $\mathrm{SO}_{2}$ and $\mathrm{w} /-\mathrm{c} /-\mathrm{G} / \mathrm{low} \mathrm{SO}_{2}$ (no $\mathrm{SO}_{2}$ additions) with treatments $\mathrm{w} /+\mathrm{c} /-\mathrm{G} /$ high $\mathrm{SO}_{2}$ and $\mathrm{w} /+\mathrm{c} /+\mathrm{G} /$ high $\mathrm{SO}_{2}\left(\mathrm{SO}_{2}\right.$ increased to $50 \mathrm{mg} / \mathrm{L}$ ), it is very clear that the presence of higher amounts of $\mathrm{SO}_{2}$ had a dramatic effect on oxygen consumption, which was also observed in the synthetic wine (treatments $\mathrm{s} /+\mathrm{c} /-\mathrm{G} /$ low $\mathrm{SO}_{2}$ and $\mathrm{s} /+\mathrm{c} /+\mathrm{G} /$ low $\mathrm{SO}_{2}$ compared to treatments $\mathrm{s} /+\mathrm{c} /-\mathrm{G} /$ high $\mathrm{SO}_{2}$ and $\mathrm{s} /+\mathrm{c} /+\mathrm{G} /$ high $\mathrm{SO}_{2}$ ). This was expected, as previous studies showed the same tendencies (Danilewicz, 2007; Danilewicz et al., 2008). The rates of consumption in treatments $\mathrm{w} /+\mathrm{c} /-\mathrm{G} /$ high $\mathrm{SO}_{2}$ and $\mathrm{w} /+\mathrm{c} /+\mathrm{G} /$ high $\mathrm{SO}_{2}$ were very similar, although treatment $\mathrm{w} /+\mathrm{c} /+\mathrm{G} /$ high $\mathrm{SO}_{2}$ did deliver a slightly faster consumption rate; this is probably due to the presence of additional GSH, serving as an extra available substrate. This was also observed in treatments $\mathrm{s} /+\mathrm{c} / \mathrm{-G} /$ low $\mathrm{SO}_{2}$ and $\mathrm{s} /+\mathrm{c} /+\mathrm{G} /$ low $\mathrm{SO}_{2}$ and treatments $\mathrm{s} /+\mathrm{c} /-\mathrm{G} /$ high $\mathrm{SO}_{2}$ and $\mathrm{s} /+\mathrm{c} /+\mathrm{G} /$ high $\mathrm{SO}_{2}$. However, this tendency was not observed in treatments $\mathrm{w} /+\mathrm{c} /-\mathrm{G} / \mathrm{low} \mathrm{SO}_{2}$ and $\mathrm{w} /+\mathrm{c} /+\mathrm{G} / \mathrm{low}$ $\mathrm{SO}_{2}$, where treatment $\mathrm{w} /+\mathrm{c} /+\mathrm{G} /$ low $\mathrm{SO}_{2}$ had a slower rate of consumption despite the presence of $\mathrm{GSH}$, which is the
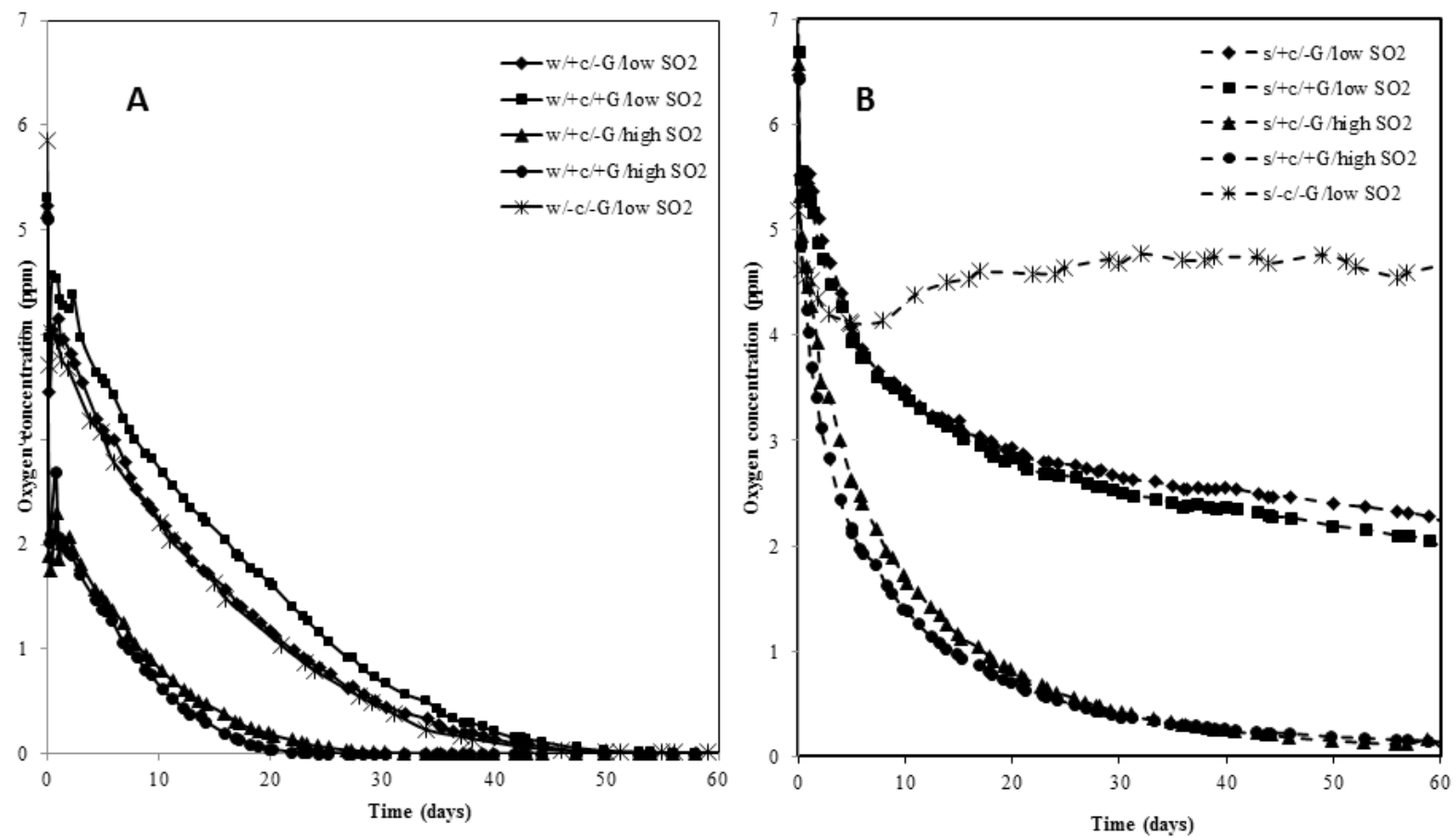

FIGURE 1

Oxygen concentration over the 60-day time period for the clarified wine (A) and the synthetic wine solution (B). The treatments

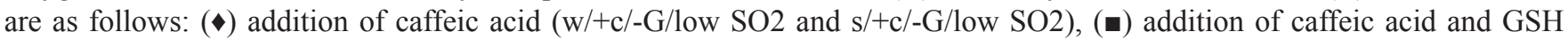
$(\mathrm{w} /+\mathrm{c} /+\mathrm{G} /$ low SO 2 and s/+c/+G/low SO2), ( $\boldsymbol{\Delta})$ addition of caffeic acid and SO2 (w/+c/-G/high SO2 and s/+c/-G/high SO2), $(\bullet)$ addition of caffeic acid, GSH and SO2 (w/+c/+G/high SO2 and s/+c/+G/high SO2), and (X) no addition (w/-c/-G/low SO2 and $\mathrm{s} /-\mathrm{c} /-\mathrm{G} /$ low $\mathrm{SO} 2$ ). 
opposite to what was found by Danilewicz et al. (2008) when they added cysteine as antioxidant compound. The reason(s) why the addition of only GSH slowed down the decrease in oxygen consumption in our clarified wine is (are) not completely clear. The tripeptide could cause slower oxygen consumption at certain concentrations, since it does not react directly with oxygen and protects the compounds usually oxidised (such as phenols), thereby reducing the oxygen consumption rate. The protection of phenols by GSH has been reported by Sonni et al. (2011), who found that GSH inhibits the formation of acetaldehyde-bridged $(+)$-catechin dimers in model wine systems. Caftaric acid $o$-quinone with catechin or the catechin oxidation to $o$-quinone product with caftaric acid can form a condensation product with a lower redox potential than its monomer constituents, which hence can be oxidised further (Cheynier et al., 1988). Whether such condensation products can be formed, and their interaction with GSH when oxidised further, should be investigated further. However, in treatments to which both GSH and $\mathrm{SO}_{2}$ had been added, these compounds showed a synergistic effect in increasing the oxygen consumption rate in both the phenol-clarified wine and the synthetic wine (treatments $\mathrm{w} /+\mathrm{c} /+\mathrm{G} /$ high $\mathrm{SO}_{2}$ and $\mathrm{s} /+\mathrm{c} /+\mathrm{G} /$ high $\mathrm{SO}_{2}$ ). The specific $\mathrm{SO}_{2}$ concentration could thus have an impact on the ability of GSH to cause higher oxygen consumption, but more research on this aspect is required.

Figure 2A shows the decrease in GSH content and the increase in GSSG content during the 60-day period. As expected, the GSH content of the clarified wine decreased at a faster rate for the treatment to which no $\mathrm{SO}_{2}$ was added (treatment $\mathrm{w} /+\mathrm{c} /+\mathrm{G} /$ low $\mathrm{SO}_{2}$ ) when compared to the treatment to which $\mathrm{SO}_{2}$ was added (treatment $\mathrm{w} /+\mathrm{c} /+\mathrm{G} /$ high $\mathrm{SO}_{2}$ ). This could indicate $\mathrm{GSH}$ becoming the preferred substrate for oxidation in the absence of $\mathrm{SO}_{2}$, or the latter protecting the GSH from oxidation. The GSH content in the synthetic wine experienced a much faster rate of decrease due to fewer oxidation substrates available in this medium. Both treatments $\mathrm{s} /+\mathrm{c} /+\mathrm{G} /$ low $\mathrm{SO}_{2}$ and $\mathrm{s} /+\mathrm{c} /+\mathrm{G} /$ high $\mathrm{SO}_{2}$ decreased at a similar rate, irrespective of the presence of $\mathrm{SO}_{2}$. At the end of the 60-day period, GSH was detected in small amounts only in treatment $\mathrm{w} /+\mathrm{c} /+\mathrm{G} /$ high $\mathrm{SO}_{2}$. GSSG formation occurred in concurrence with the decrease in GSH concentrations in both the clarified and synthetic wine (Fig. 2A). However, the formation of GSSG was slower in the clarified wine compared to the synthetic wine. The formation of GSSG was also hindered by the presence of higher amounts of $\mathrm{SO}_{2}$ (treatments $\mathrm{w} /+\mathrm{c} /+\mathrm{G} /$ high $\mathrm{SO}_{2}$ and $\mathrm{s} /+\mathrm{c} /+\mathrm{G} /$ high $\mathrm{SO}_{2}$ ). The reason for this is not clear, but the same trend has also been found by Du Toit et al. (2007) in juice and could be due to the antioxidant effect of $\mathrm{SO}_{2}$. Other possible oxidation products of GSH are GRP and glutathionyl-caffeic acid. Low variations in GRP and glutathionyl-caffeic acid concentrations between the beginning and the end of the trial were detected under these experimental conditions in all the treatments (maximum variation $2.2 \mathrm{mg} / \mathrm{L}$ ), and were not significantly different between treatments (Table 3 ). These low variations were probably due to the continued equilibrium shift between GRP and caftaric acid, especially at a low pH (Ribéreau-Gayon et al., 2006), or due to these compounds not being influenced by the treatments.

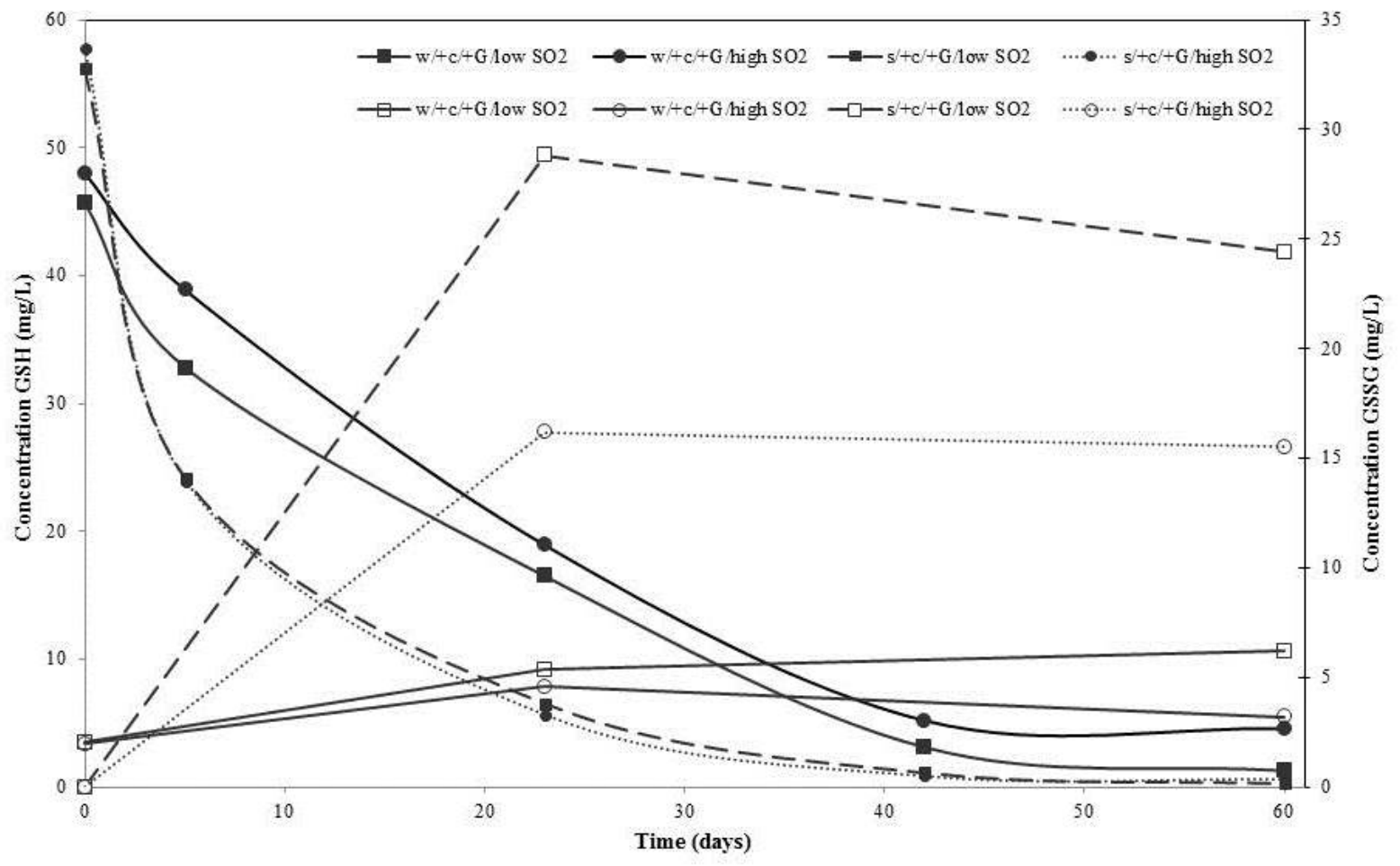

FIGURE 2A

Decrease in reduced glutathione (GSH) (filled symbols) and increase in oxidised glutathione (GSSG) (unfilled symbols) for the clarified wine (solid line) and synthetic wine solution (broken line). The treatments are as follows: ( $\mathbf{\square})$ addition of caffeic acid and GSH (w/+c/+G/low SO2 and s/+c/+G/low SO2), (•) addition of caffeic acid, GSH and SO2 (w/+c/+G/high SO2 and $\mathrm{s} /+\mathrm{c} /+\mathrm{G} /$ high $\mathrm{SO} 2)$ 


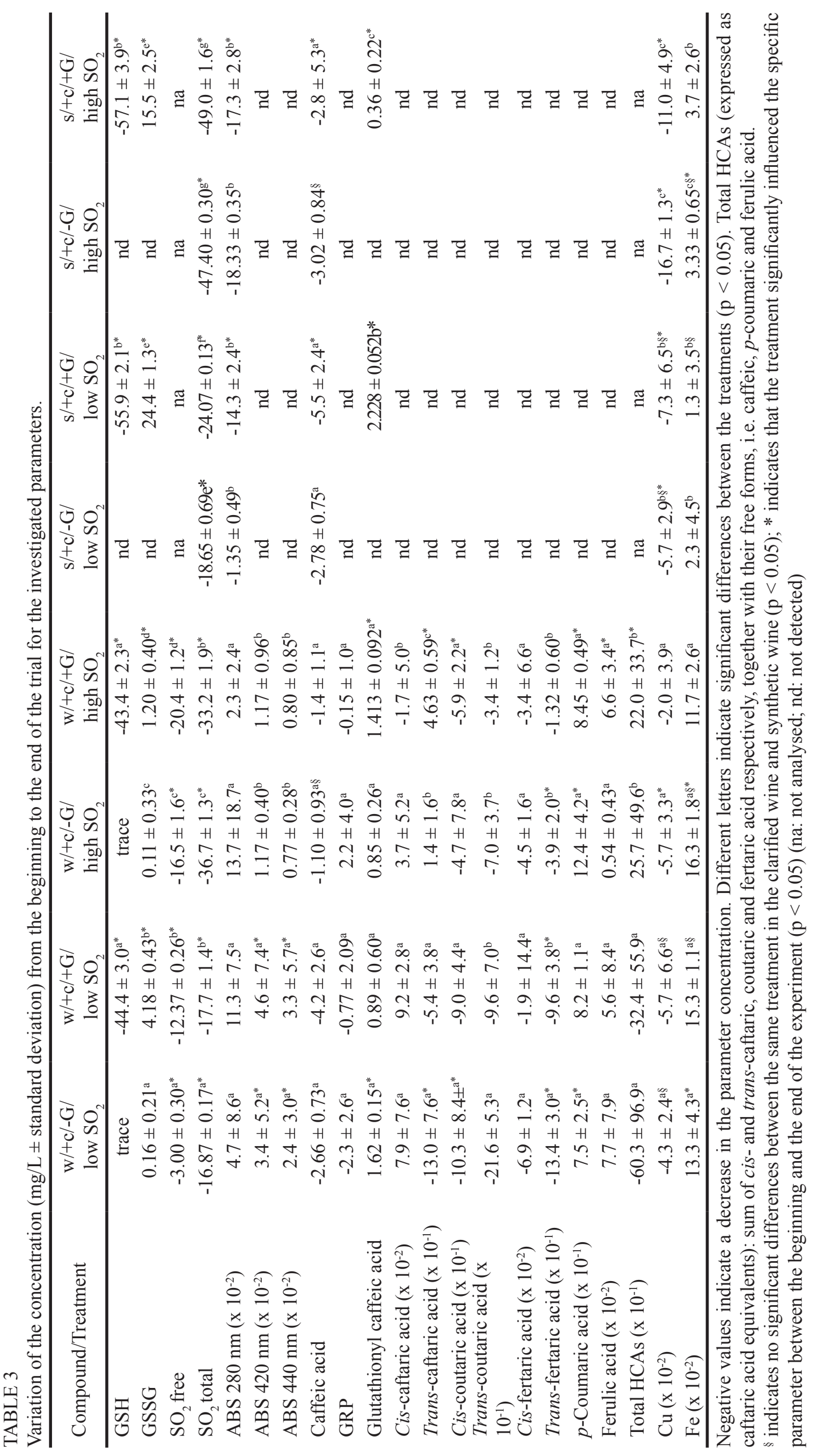


Moreover, the clarified wine would still contain low concentrations of other hydroxycinnamic acids or unknown oxidation products, which could also have reacted with the residual GSH, forming other unknown products that were not measured. The amount of GSSG, GRP and glutathionylcaffeic acid formed thus did not correspond to the amount of GSH that disappeared. For the synthetic wine, the formation of GSSG accounted for approximately $43 \%$ and $27 \%$ of the loss of $\mathrm{GSH}$ in treatments $\mathrm{s} /+\mathrm{c} /+\mathrm{G} /$ low $\mathrm{SO}_{2}$ and $\mathrm{s} /+\mathrm{c} /+\mathrm{G} /$ high $\mathrm{SO}_{2}$ respectively. For the clarified wine, the percentage converted was even lower. Sonni et al. (2011) have reported the involvement of glutathione in the formation of a methylglutathionyl-methine-(p)-catechin complex in model wine systems containing catechin. The formation of such complexes with phenols could be a possible source of the disappearance of GSH from our clarified wine. Furthermore, GRP has also been reported to undergo hydrolysis in model wine and in real wine (Cejudo-Bastante et al., 2010), which could lead to misconceptions regarding the fate of GSH in white wines.

Figure 2B shows the evolution of total $\mathrm{SO}_{2}$ concentration over time. A significant decrease in total $\mathrm{SO}_{2}$ was observed in all cases, although a noticeably faster rate of decrease was observed in the synthetic wine compared to the clarified wine. The decrease in $\mathrm{SO}_{2}$ concentrations was not dependent on the addition of GSH. The protective effect exerted by GSH on the formation of oxidative compounds is known (Sonni et al., 2011), as well as the antioxidant activity performed by $\mathrm{SO}_{2}$ and its interaction with oxygen and polyphenols (Danilewicz, 2007), but the interaction between $\mathrm{SO}_{2}$ and $\mathrm{GSH}$ still needs further attention. Some residual $\mathrm{SO}_{2}$ was still present after the 60 -day period (more than $10 \mathrm{mg} / \mathrm{L}$ total $\mathrm{SO}_{2}$, of which less than $4 \mathrm{mg} / \mathrm{L}$ was free $\mathrm{SO}_{2}$ ) in the clarified wine treatments to which additional $\mathrm{SO}_{2}$ had been added.

Absorbance values measured at $420 \mathrm{~nm}$ (brown colour) and $440 \mathrm{~nm}$ (yellow colour) were significantly higher in treatments $\mathrm{w} /+\mathrm{c} /-\mathrm{G} /$ low $\mathrm{SO}_{2}$ and $\mathrm{w} /+\mathrm{c} /+\mathrm{G} /$ low $\mathrm{SO}_{2}$ compared to treatments $\mathrm{w} /+\mathrm{c} /-\mathrm{G} /$ high $\mathrm{SO}_{2}$ and $\mathrm{w} /+\mathrm{c} /+\mathrm{G} /$ high $\mathrm{SO}_{2}$ (Table 3). An increase in the absorbance values is an indication of oxidative coloration occurring in the wine (Skouroumounis et al., 2005). This is due to the oxidation of phenolic compounds to their corresponding $o$-quinones, in varying degrees of polymerisation, causing yellow-brown coloration (Du Toit et al., 2006). It would seem that the presence of neither caffeic acid nor GSH had a significant effect on these absorbance values. However, $\mathrm{SO}_{2}$ is well known to have a bleaching property (Du Toit et al., 2006), which clearly had an effect on the coloured compounds in this study, as the treatments containing more $\mathrm{SO}_{2}$ (treatments $\mathrm{w} /+\mathrm{c} /-\mathrm{G} /$ high $\mathrm{SO}_{2}$ and $\mathrm{w} /+\mathrm{c} /+\mathrm{G} /$ high $\mathrm{SO}_{2}$ ) had lower absorbance values. For the synthetic wine solution, the absorbance values detected at $420 \mathrm{~nm}$ and $440 \mathrm{~nm}$ were lower than $0.005 \mathrm{AU}$ and thus are not presented. While a number of publications have reported a correlation between an increase in browning and a decrease in $\mathrm{SO}_{2}$ levels (Bradshaw et al. 2001; Godden et al., 2001; Bradshaw et al., 2004), the exact mechanism of this bleaching effect in wine is not known, but it could be due to the reduction of the $o$-quinones (Danilewicz et al., 2008) or the antioxidant effect of $\mathrm{SO}_{2}$.

The presence of an antioxidant seemed to have preserved the total HCA content in the clarified wine (Table 3). In the

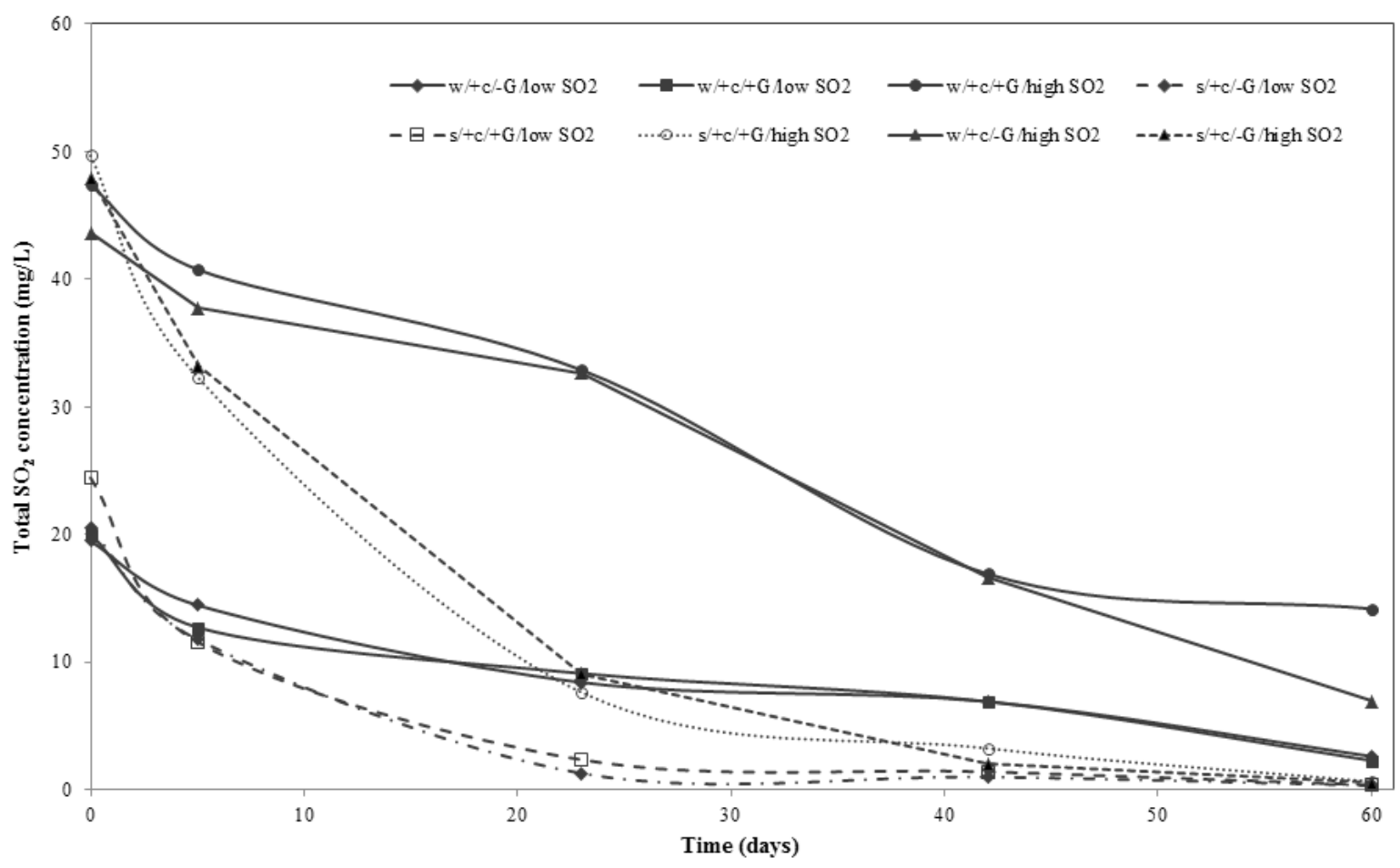

FIGURE 2B

Decrease in total SO2 concentration of clarified wine (solid line) and synthetic wine solution (broken line). The treatments are as follows: ( $\downarrow$ ) addition of caffeic acid (w/+c/-G/low SO2 and s/+c/-G/low SO2), (घ) addition of GSH (w/+c/+G/low SO2 and $\mathrm{s} /+\mathrm{c} /+\mathrm{G} /$ low SO2), $(\boldsymbol{\Delta})$ addition of SO2 (w/+c/-G/high SO2 and s/+c/-G/high SO2), (•) addition of GSH and SO2 (w/+c/+G/ high $\mathrm{SO} 2$ and $\mathrm{s} /+\mathrm{c} /+\mathrm{G} /$ high $\mathrm{SO} 2$ ). 
treatments in which the $\mathrm{SO}_{2}$ content was low (treatments $\mathrm{w} /+\mathrm{c} /-\mathrm{G} /$ low $\mathrm{SO}_{2}$ and $\mathrm{w} /+\mathrm{c} /+\mathrm{G} /$ low $\mathrm{SO}_{2}$ ), the total HCA content decreased in comparison to the treatments to which a larger amount of $\mathrm{SO}_{2}$ was added. In the presence of GSH (treatment $\mathrm{w} /+\mathrm{c} /+\mathrm{G} /$ low $\mathrm{SO}_{2}$ ), the decrease in total HCAs was lower $\left(-32.4 \times 10^{-1} \mathrm{mg} / \mathrm{L}\right)$ when compared to low $\mathrm{SO}_{2}$ content and no GSH addition $\left(-60.3 \times 10^{-1} \mathrm{mg} / \mathrm{L}\right)$, although this difference was not significant. The added $\mathrm{SO}_{2}$ thus had a much stronger and significant effect in the protection of total HCAs against oxidation in the clarified wine compared to GSH, but small, non-significant changes were observed frequently with most cinnamic acid derivatives (Table 3).

Figure $3 \mathrm{~A}$ shows a principal component analysis (PCA) constructed from the analytical data of the clarified wine at the beginning and the end of the 60-day period. GSH, copper, $\mathrm{SO}_{2}$, oxygen and caffeic acid were correlated positively in the clarified wine. The PC1 and PC2 explained $72 \%$ of the variance. This illustrates the effect that copper has on wine oxidation, confirming results found by Danilewicz (2007). Among the investigated parameters, GSSG and absorbance at $420 \mathrm{~nm}$ and $440 \mathrm{~nm}$, normally linked with wine oxidation, were positively correlated with each other and negatively correlated with the above-mentioned characteristics. As in the clarified wine, $\mathrm{GSH}$, free $\mathrm{SO}_{2}$, copper and oxygen were also positively correlated with each other in the synthetic wine and negatively correlated with GSSG and glutathionylcaffeic acid (Fig. 3B).

Figure $3 \mathrm{C}$ is a $\mathrm{PCA}$ constructed from the data acquired for oxygen, GSH, total $\mathrm{SO}_{2}$, caffeic acid and absorbance at $280 \mathrm{~nm}$, using data from all five sampling dates for both the clarified and the synthetic wine. As in the previous PCA plots, PC1 represents time, in this case explaining $44.91 \%$ of the variance, and PC2 represents the experimental conditions, explaining $28.27 \%$ of the variance. A clear separation was observed for PC2, separating the two matrices. For the clarified wine, an evident and chronological separation was observed due to PC1 for most treatments. Higher variations were observed in the synthetic wine. However, one of the aims of this study was to observe whether some of general trends observed in synthetic wine are also observed in real wine, due to the fact that synthetic wines are often used in such studies because of their simplicity of use. This was the case for the evolution of certain compounds in this study, as observed in PC1 in Fig. 3C, which adds credibility to the usage of synthetic wines in these types of studies. However, further research on this topic is required.

A positive correlation was observed between oxygen consumption and GSH (0.64), $\mathrm{SO}_{2}(0.44)$ and copper (0.68), while there was a negative correlation with absorbance values measured at $280 \mathrm{~nm}(-0.15), 420 \mathrm{~nm}(-0.75)$ and 440 $\mathrm{nm}(-0.73)$. In the synthetic wine, oxygen was positively correlated with GSH (0.71), $\mathrm{SO}_{2}(0.68)$ and copper (0.49), and negatively correlated with the absorbance measured at $280 \mathrm{~nm}(-0.63)$. This further corroborates the roles these compounds play in the oxidation of Sauvignon blanc wines.

\section{Young wines}

For the thirteen oxygenated Sauvignon blanc wines, oxygen consumption was measured over time. For the treatments to which no $\mathrm{SO}_{2}$ additions were made (Fig. 4A), most of the

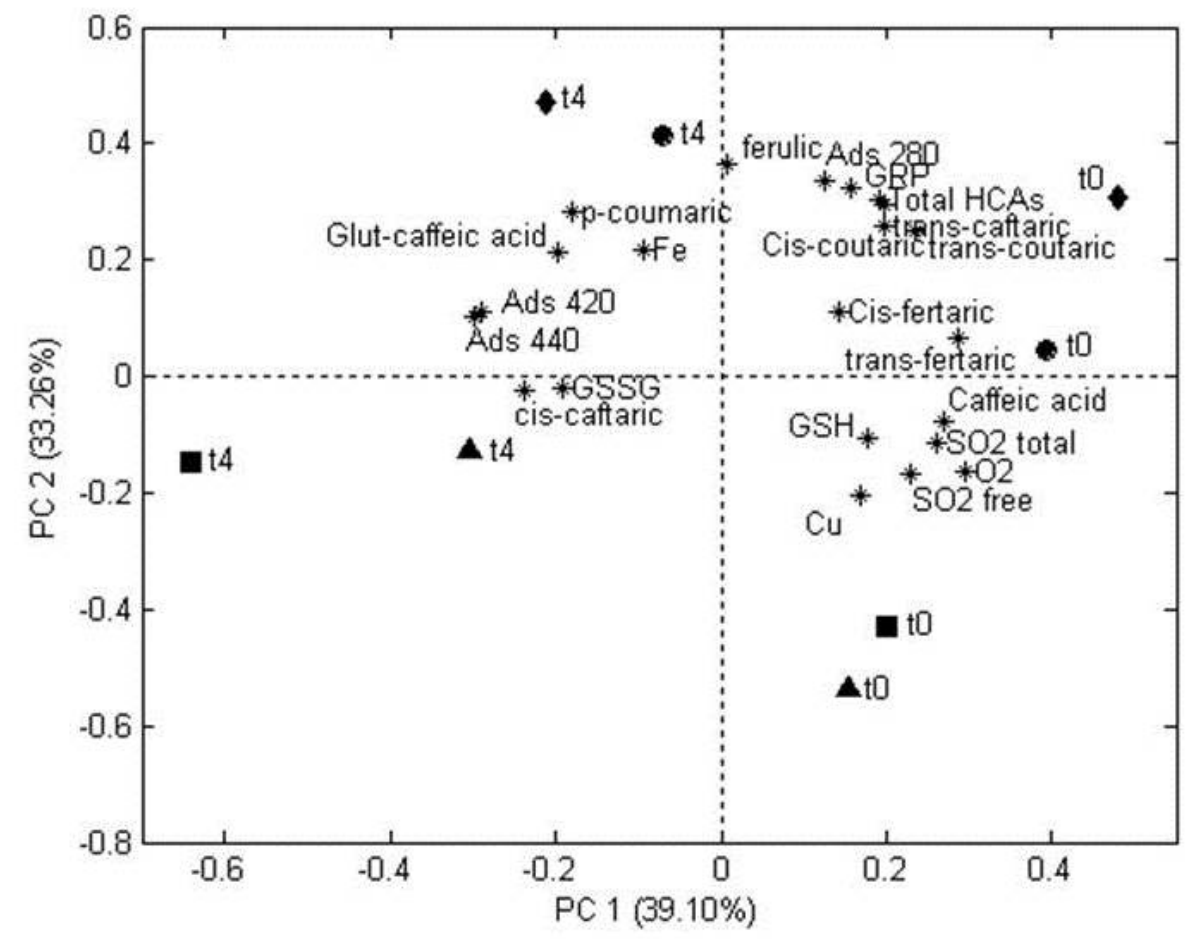

FIGURE 3A

Biplot of clarified wine. PC1: time; PC2: experimental conditions. Only data from the beginning and the end sampling dates were used to construct this PCA. Treatments are as follows: ( $\downarrow)$ addition of caffeic acid (w/+c/-G/low SO2 and s/+c/-G/low $\mathrm{SO} 2),(\boldsymbol{\square})$ addition of caffeic acid and GSH (w/ $+\mathrm{c} /+\mathrm{G} /$ low SO2 and s/+c/+G/low SO2), ( $\boldsymbol{\Delta})$ addition of caffeic acid and SO2 (w/+c/-G/high SO2 and s/+c/-G/high SO2), (•) addition of caffeic acid, GSH and SO2 (w/+c/+G/high SO2 and s/+c/+G/high $\mathrm{SO} 2)$. 


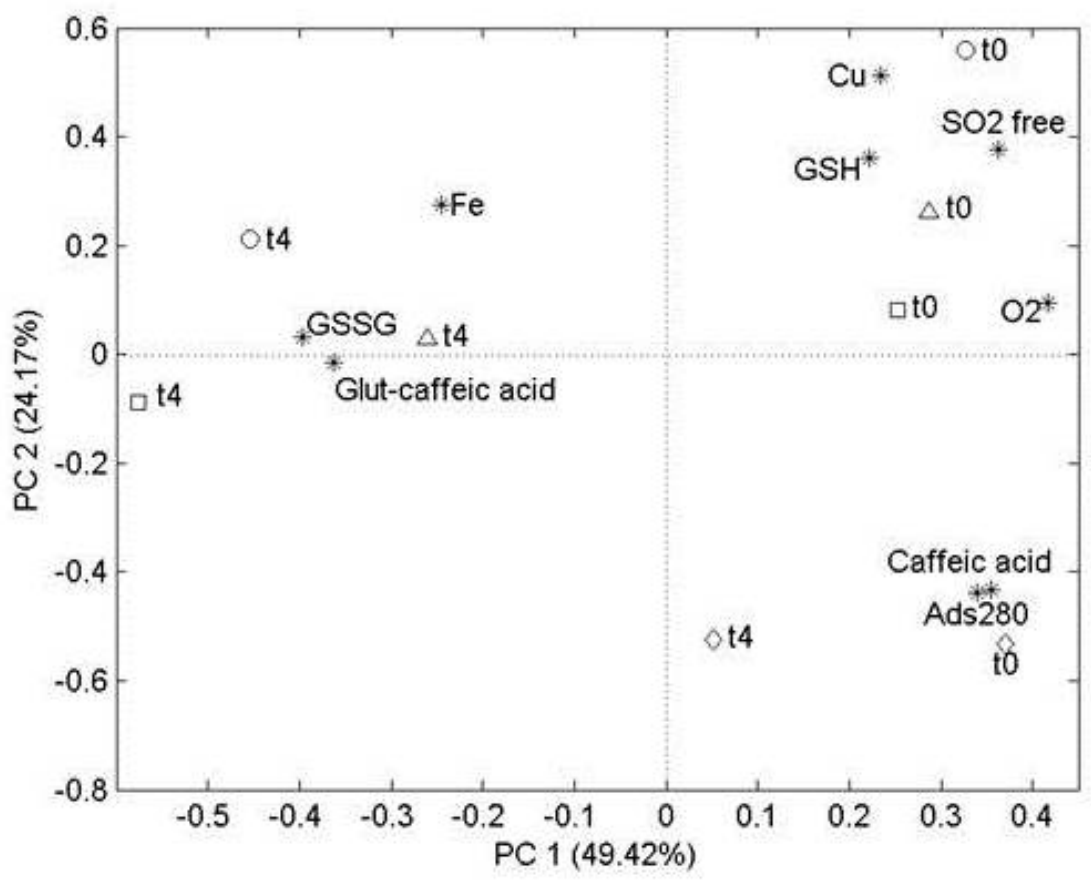

FIGURE 3B

Biplot of synthetic wine solution. PC1: time; PC2: experimental conditions. Only data from the beginning and the end sampling dates were used to construct this PCA. Treatments are as follows: ( $\downarrow)$ addition of caffeic acid (w/+c/-G/low SO2 and s/+c/-G/ low SO2), ( $\mathbf{-})$ addition of caffeic acid and GSH (w/+c/+G/low SO2 and s/+c/+G/low SO2), ( $\mathbf{\Delta})$ addition of caffeic acid and SO2 (w/+c/-G/high SO2 and s/+c/-G/high SO2), (•) addition of caffeic acid, GSH and SO2 (w/+c/+G/high SO2 and s/+c/+G/ high SO2).

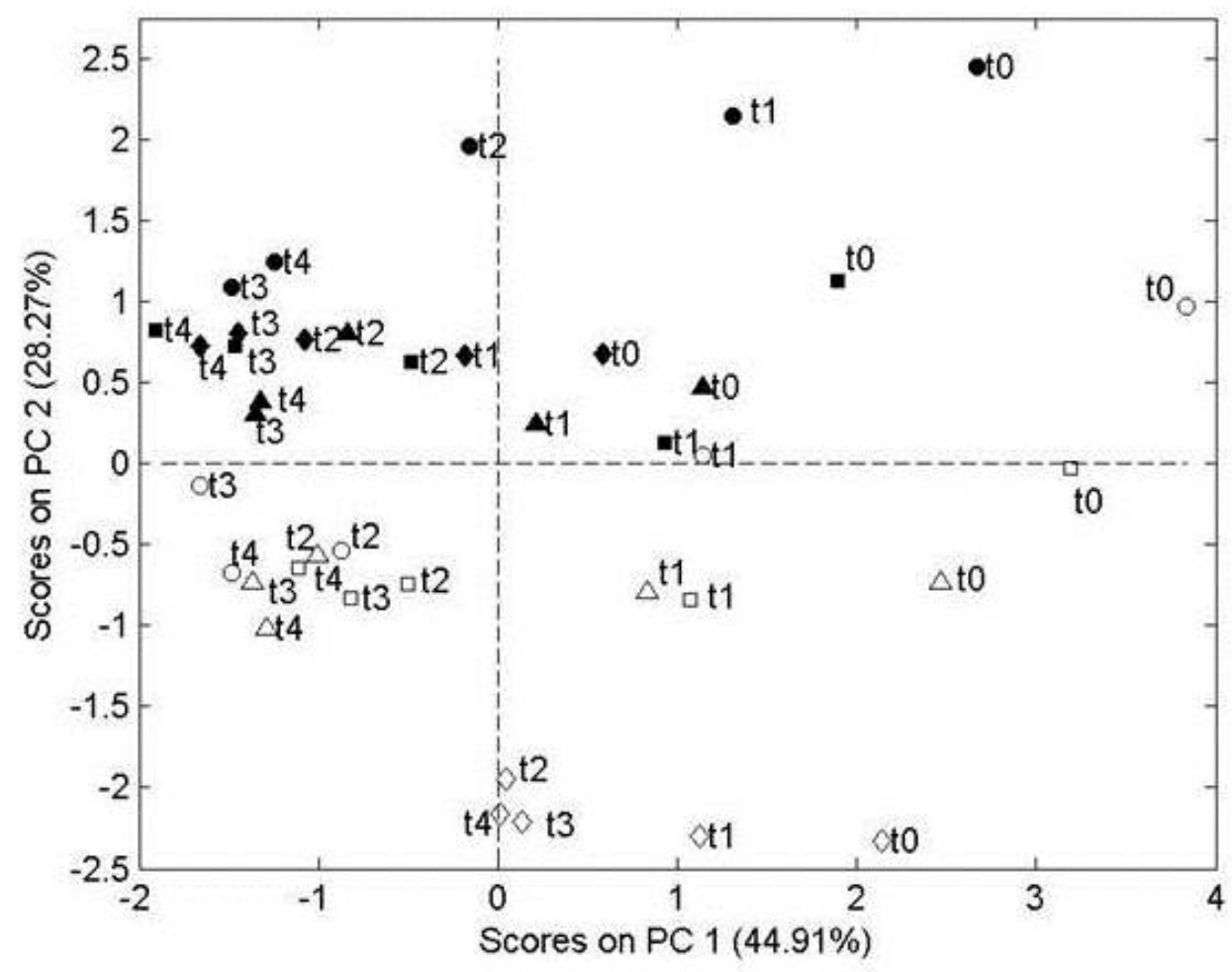

FIGURE 3C

PCA of clarified wine (filled symbols) and synthetic wine solution (unfilled symbols). PC1: time; PC2: experimental conditions. The data used for the construction of PCA (C) were the concentrations of oxygen, GSH, total SO2, caffeic acid and the absorbance at $280 \mathrm{~nm}$ for five sampling times (t0, t1, t2, t3, t4). Treatments are as follows: $(\downarrow)$ addition of caffeic acid (w/+c/-G/ low SO2 and s/+c/-G/low SO2), (汭) addition of caffeic acid and GSH (w/+c/+G/low SO2 and s/+c/+G/low SO2), ( $\mathbf{\Delta})$ addition of caffeic acid and SO2 (w/+c/-G/high SO2 and s/+c/-G/high SO2), (•) addition of caffeic acid, GSH and SO2 (w/+c/+G/high $\mathrm{SO} 2$ and $\mathrm{s} /+\mathrm{c} /+\mathrm{G} /$ high $\mathrm{SO} 2)$. 
oxygen was consumed by day 40, with the exception of wines 1,4 and 7, in which the dissolved oxygen concentrations still decreased up to the end of the trial (day 60). As expected, the addition of $\mathrm{SO}_{2}$ increased the oxygen consumption rate (Fig. 4B). Indeed, after 35 days, the dissolved oxygen content in all the analysed wines was consumed; some of the wines had already consumed all of the dissolved oxygen by day 15 . The average oxygen consumption rate observed for the wines to which $\mathrm{SO}_{2}$ had been added (0.47) was significantly different from that of the wines to which no $\mathrm{SO}_{2}$ had been added $(0.19)(\mathrm{p}=0.023)$. This again supports the important role of $\mathrm{SO}_{2}$ in the consumption of oxygen in wine by accelerating the oxidation effect and thus removing dissolved oxygen from the wine.

No ascorbic acid was detected in any of the thirteen wines investigated. The average variation in GSH, GSSG, $\mathrm{SO}_{2}$, oxygen concentration and absorbance values at $280 \mathrm{~nm}$, $420 \mathrm{~nm}$ and $440 \mathrm{~nm}$ over time is reported in Table 4. No GSH was detected in any of the wines after the 60-day period, irrespective of whether or not $\mathrm{SO}_{2}$ had been added. Although the GSSG concentration increased from the beginning to the end in all the treatments, the increase was mostly lower in the wines to which $\mathrm{SO}_{2}$ had been added, again indicating the inhibiting effect of $\mathrm{SO}_{2}$ on the formation of GSSG. Average losses in free and total $\mathrm{SO}_{2}$ concentrations were observed in all the wines after the 60-day trial. It would seem as if more

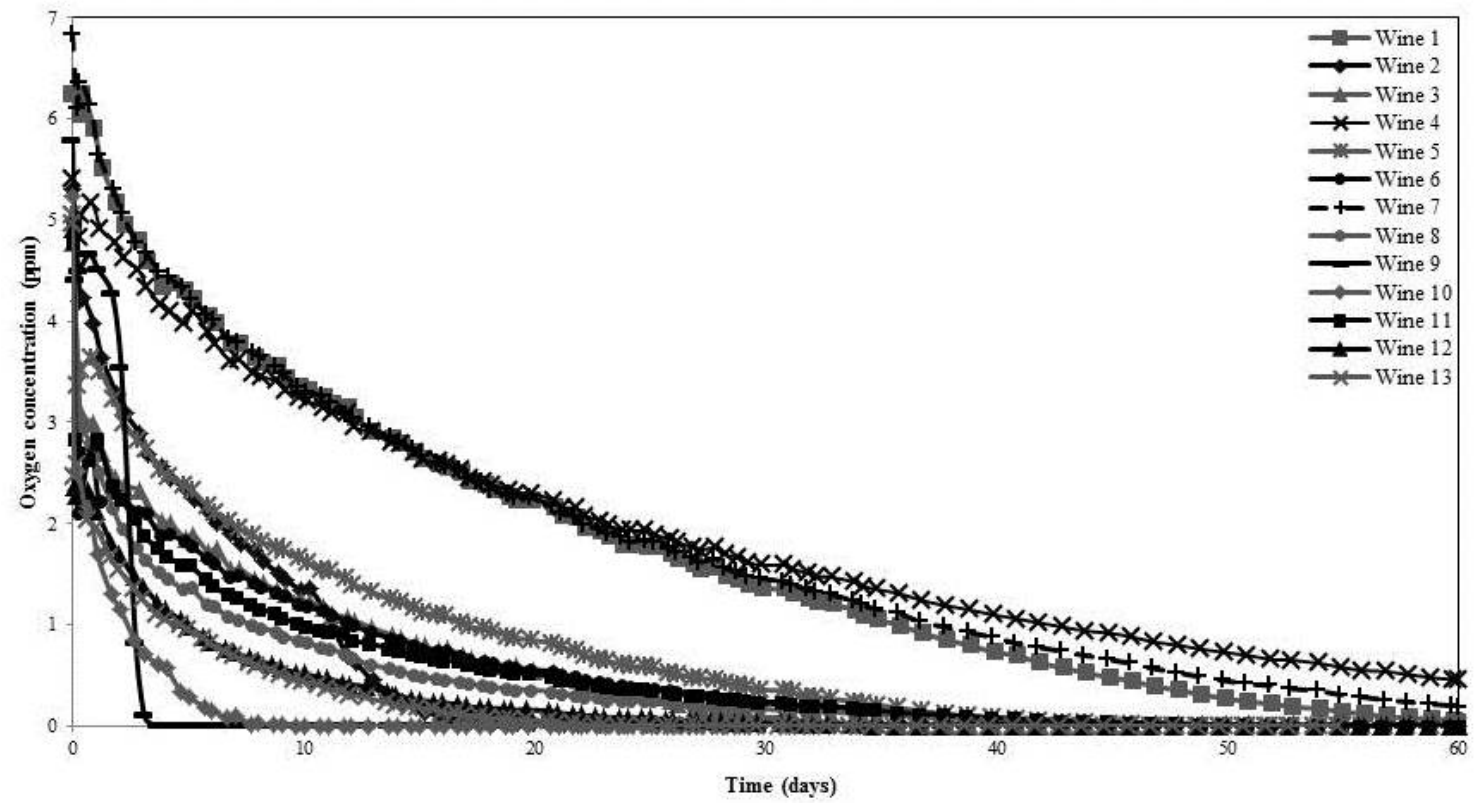

FIGURE 4A

Evolution of the oxygen concentration of 13 young Sauvignon blanc wines oxygenated in the absence of SO2.

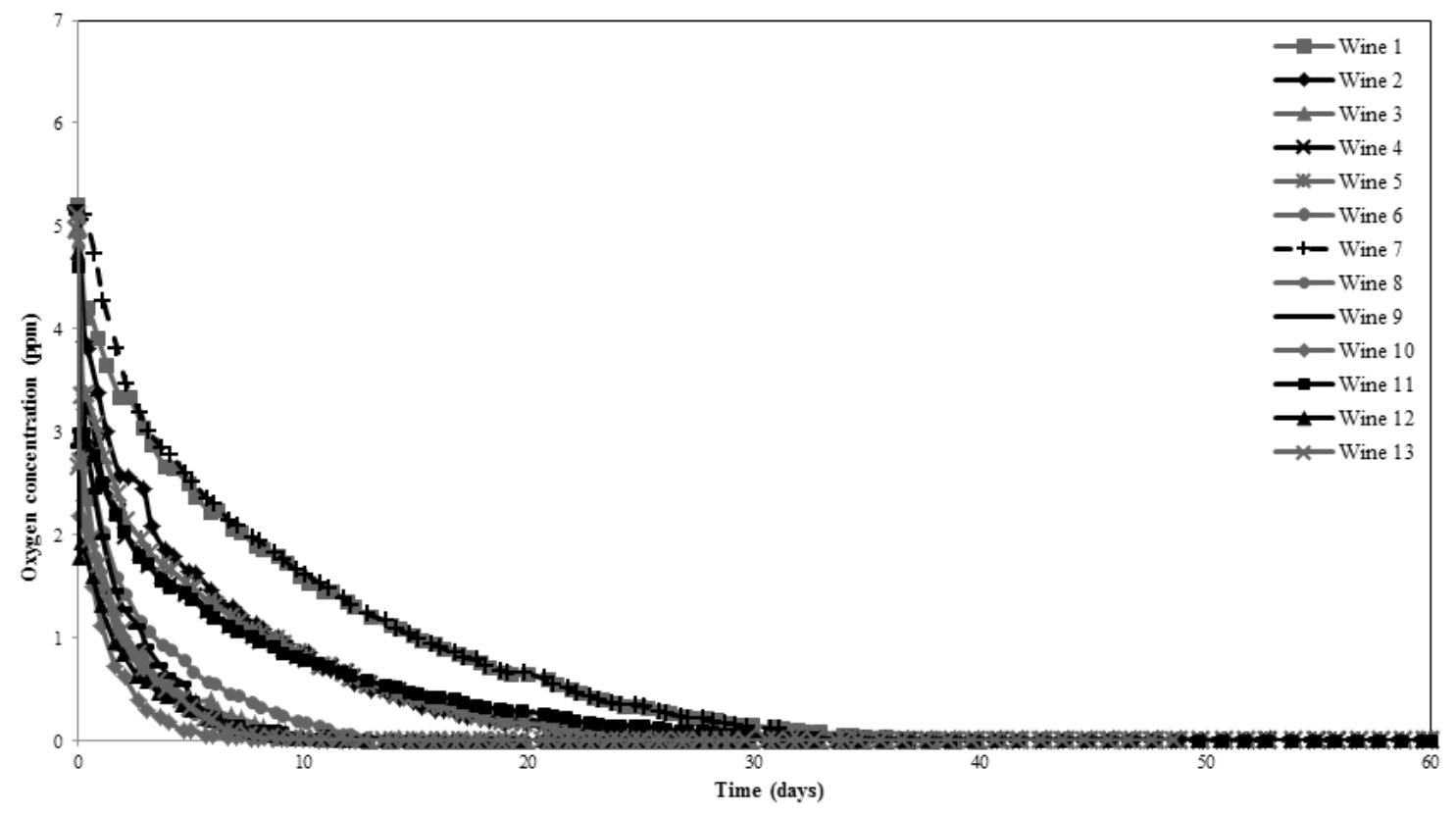

FIGURE 4B

Evolution of the oxygen concentration of 13 Sauvignon blanc wines oxygenated after the addition of $30 \mathrm{mg} / \mathrm{L} \mathrm{SO}$. 
TABLE 4

Average variation in concentration ( \pm standard deviation) between the beginning and the end of the trial for investigated compounds.

\begin{tabular}{|c|c|c|}
\hline \multirow{2}{*}{ Compound } & \multicolumn{2}{|c|}{ Average concentration $(\mathrm{mg} / \mathrm{L})$} \\
\hline & No $\mathrm{SO}_{2}$ addition & $\mathrm{SO}_{2}$ addition \\
\hline Oxygen & $-5.27 \pm 0.32 *$ & $-4.98 \pm 0.10^{*}$ \\
\hline $\mathrm{SO}_{2}$ free $^{\mathrm{a}}$ & $-5.84 \pm 1.43 *$ & $-15.38 \pm 2.71^{*}$ \\
\hline $\mathrm{SO}_{2}$ total $^{\mathrm{a}}$ & $-20.57 \pm 5.26^{*}$ & $-38.10 \pm 4.69^{*}$ \\
\hline GSH & $-6.07 \pm 2.37$ & $-9.21 \pm 2.56$ \\
\hline $\mathrm{GSSG}^{\mathrm{a}}$ & $2.07 \pm 0.17^{*}$ & $1.48 \pm 0.30^{*}$ \\
\hline $\mathrm{GRP}^{\mathrm{b}}$ & $0.97 \pm 1.57$ & $3.26 \pm 1.92$ \\
\hline Glutathionyl-caffeic acid & $1.88 \pm 0.57^{*}$ & $2.08 \pm 0.74^{*}$ \\
\hline Caffeic acid & $-1.40 \pm 1.66$ & $-0.37 \pm 0.80$ \\
\hline Catechin & $-4.97 \pm 2.88^{*}$ & $-4.68 \pm 3.63 *$ \\
\hline Cis-caftaric acid & $-0.44 \pm 0.21$ & $-0.76 \pm 0.51^{*}$ \\
\hline Trans-caftaric acid & $0.22 \pm 1.11$ & $0.47 \pm 0.90$ \\
\hline Cis-coutaric acid & $-1.06 \pm 0.43$ & $-0.97 \pm 0.59$ \\
\hline Trans-coutaric acid & $-0.83 \pm 0.83$ & $-0.69 \pm 0.82$ \\
\hline Cis-fertaric acid & $-0.047 \pm 0.050$ & $-0.106 \pm 0.038^{*}$ \\
\hline Trans-fertaric acid & $0.20 \pm 0.12$ & $0.298 \pm 0.083^{*}$ \\
\hline Coumaric acid & $-0.21 \pm 0.62$ & $0.45 \pm 0.90$ \\
\hline Ferulic acid & $-0.0012 \pm 0.2097$ & $0.55 \pm 0.75$ \\
\hline Total HCAs ${ }^{\mathrm{a}}$ & $-3.90 \pm 5.79$ & $3.38 \pm 3.44$ \\
\hline $\mathrm{Cu}$ & $-0.052 \pm 0.13^{*}$ & $-0.053 \pm 0.016^{*}$ \\
\hline \multirow[t]{2}{*}{$\mathrm{Fe}^{\mathrm{b}}$} & $-0.076 \pm 0.051$ & $-0.016 \pm 0.044$ \\
\hline & \multicolumn{2}{|c|}{ Average absorbance (AU) } \\
\hline ABS $280 \mathrm{~nm}$ & $2.74 \pm 0.72 *$ & $2.99 \pm 0.92 *$ \\
\hline ABS $420 \mathrm{~nm}^{\mathrm{b}}$ & $0.050 \pm 0.012 *$ & $0.0355 \pm 0.0073^{*}$ \\
\hline ABS $440 \mathrm{~nm}^{\mathrm{a}}$ & $0.036 \pm 0.010^{*}$ & $0.0240 \pm 0.056^{*}$ \\
\hline
\end{tabular}

* indicates the treatment significantly influenced the specific parameter between the beginning and the end of the experiment $(p<0.05) ;{ }^{a}$ significant difference between treatments $(p<0.05) ;{ }^{b}$ significant difference between treatments $(p<0.10)$. Total HCAs (expressed as caftaric acid equivalents): sum of cis- and trans-caftaric, coutaric and fertaric acid, together with their free forms, i.e. caffeic, $p$-coumaric and ferulic acid

$\mathrm{SO}_{2}$ was lost in the treatments to which $\mathrm{SO}_{2}$ had been added; this is expected, as more $\mathrm{SO}_{2}$ would have been available for oxidation reactions. Changes in colour were monitored at $420 \mathrm{~nm}$ and $440 \mathrm{~nm}$ (Table 4). Higher average absorbance values generally were detected in the wines to which no $\mathrm{SO}_{2}$ had been added, indicating an oxidised colour development. The absorbance measurements increased at $280 \mathrm{~nm}$ (average increase 2.8 A.U.) for almost all the wines, irrespective of the higher $\mathrm{SO}_{2}$ concentration.

The average level of catechin, and of cis-caftaric and cisfertaric acids in the case of $\mathrm{SO}_{2}$ additions, decreased during the 60-day incubation. Interestingly, the average levels of trans-fertaric acid actually showed minimal, but significant, increases during the trial. However, the antioxidant capacity of ferulic acid is not well known in wine (Kilmartin et al., 2001; Waterhouse, 2002; Li et al., 2008) and should be investigated further. As expected, the amount of glutathionyl caffeic acid also increased during the oxidation process (Table 4).

The $\mathrm{SO}_{2}$ treatment (addition or omission) had a significant effect on free and total $\mathrm{SO}_{2}$, absorbance at $420 \mathrm{~nm}$ and $440 \mathrm{~nm}, \mathrm{GSH}, \mathrm{GSSG}, \mathrm{GRP}$, total HCAs and Fe (Table 4), linking to the results observed in the synthetic and clarified wine. A PCA constructed from the chemical composition of the 13 young Sauvignon blanc wines also indicated the correlation between $\mathrm{GSH}, \mathrm{Cu}$, and free and total $\mathrm{SO}_{2}$, which was negatively correlated with GSSG and absorbance at 420 $\mathrm{nm}$ and $440 \mathrm{~nm}$ (Fig. 5). Oxygen consumption, according to the Pearson correlations, correlated positively with copper (0.60), GSH (0.24) and total $\mathrm{SO}_{2}(0.52)$, while it was negatively correlated with caffeic acid $(-0.30)$ and the absorbance values at $280 \mathrm{~nm}(-0.39), 420 \mathrm{~nm}(-0.11)$ and 440 $\mathrm{nm}(-0.11)$. This could indicate that absorbance values at 420 and $440 \mathrm{~nm}$ are not always a good indicator of oxidation in white wine. One of the main protective functions of $\mathrm{SO}_{2}$ in wine is to react with hydrogen peroxide. This would limit further oxidation of ethanol and other saturated hydroxyl compounds (Boulton et al., 1996). $\mathrm{SO}_{2}$ is also known to reduce oxidised phenolics (Danilewicz et al., 2008). The 


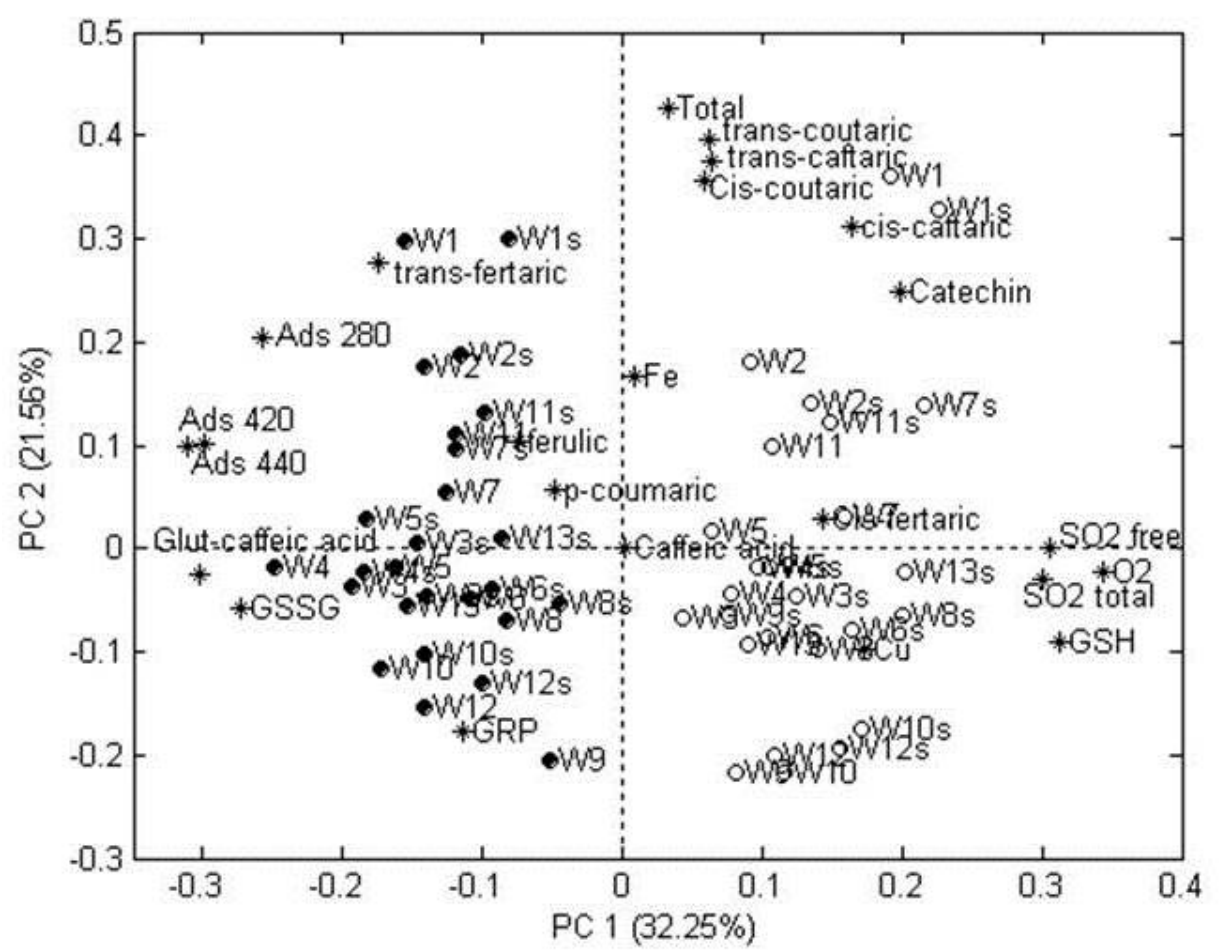

FIGURE 5

PCA of the 13 young Sauvignon blanc wines. Numbers marked with "s" indicate treatments with added SO2. Unfilled symbols indicate measurements taken at the beginning of the trial, while filled symbols represent measurements taken at end of the trial. PC1: time; PC2: experimental conditions.

important role played by $\mathrm{SO}_{2}$ during the oxidation of South African Sauvignon blanc wines has been confirmed by this study, but further research regarding this aspect is required.

\section{CONCLUSIONS}

The interaction of the different wine constituents in an oxidative environment showed some interesting traits. Even though GSH is seen as an effective antioxidant, it would seem as if the effect of $\mathrm{SO}_{2}$ was superior and played a very influential role in most of the parameters measured. The oxygen consumption rate especially was influenced by the $\mathrm{SO}_{2}$ content, as higher $\mathrm{SO}_{2}$ concentrations led to significantly higher consumption rates in both the synthetic wine and the clarified wine. GSH alone was not an effective consumption accelerator, but a slight synergistic effect was observed in combination with $\mathrm{SO}_{2}$. Sulphur dioxide also lowered the formation of GSSH and browning during oxidation. Interestingly, the amount of oxidised GSH products formed did not coincide with the amount of GSH lost during the trial; however, the possibility of other products being formed, as well as the degradation of GRP and related products, should be investigated further. Even though the clarified wine was treated to remove most of the wine constituents, the remaining antioxidant content of the clarified wine still had a significant effect, thereby limiting the ability to compare the two matrices. Even though the addition of $\mathrm{SO}_{2}$ did increase the rate of oxygen consumption, the inherent composition of the wine played a large role in oxygen consumption in the 13 young wines. The question thus arises how applicable synthetic wine studies are to a real-wine situation, and this should also be investigated further.

Future white wine oxidation studies should focus on oxidation compounds deriving from phenolic oxidation. Moreover, the role played by oxidation catalysts, such as $\mathrm{Cu}$ and $\mathrm{Fe}$, in this regard should also be examined.

\section{LITERATURE CITED}

Bradshaw, M.P., Scollary, G.R. \& Prenzler, P.D., 2001. Ascorbic acidinduced browning of $(+)$-catechin in a model wine system. J. Agric. Food Chem. 49, 934-939.

Bradshaw, M.P., Scollary, G.R. \& Prenzler, P.D., 2004. Examination of the sulfur dioxide-ascorbic acid anti-oxidant system in a model white wine matrix. J. Sci. Food Agric. 84, 318-324.

Boulton, R.B., Singleton, V.L., Bisson, L.F. \& Kunkee, R.E., 1996. Principles and practices of winemaking. Chapman \& Hall, New York.

Cejudo-Bastante, M.J., Pérez-Coello, M.S. \& Hermosín-Gutiérrez, I., 2010. Identification of new derivatives of 2-S-glutathionylcaftaric acid in aged white wines by HPLC-DAD-ESI-MS. J. Agric. Food Chem. 58, 1148311492.

Cheynier, V., Osse, C. \& Rigaud, J., 1988. Oxidation of grape juice phenolic compounds in model solutions. J. Food Sci. 53, 1729-1732.

Cilliers, J.J.L. \& Singleton, V.L., 1989. Nonenzymatic autooxidative phenolic browning reactions in a caffeic acid model system. J. Agric. Food Chem. 37, 890-896.

Cilliers, J.J.L. \& Singleton, V.L., 1990a. Caffeic acid autoxidation and the effects of thiols. J. Agric. Food Chem. 38, 1789-1796.

Cilliers, J.J.L. \& Singleton, V.L., 1990b. Nonenzymatic autoxidative reaction of caffeic acid in wine. Am. J. Enol. Vitic. 41, 84-86.

Cilliers, J.J.L. \& Singleton, V.L., 1991. Characterization of the products of nonenzymic autoxidative phenolic reactions in a caffeic acid model system. J. Agric. Food Chem. 39, 1298-1303. 
Compendium of international methods of analysis - OIV, 2010. Method OIV-MA-F-AS322-06-CUIVRE for copper determination Resolution Oeno, 56.

Compendium of international methods of analysis - OIV, 2010. Method OIV-MA-F-AS322-05-FER for iron determination Resolution Oeno, 55.

Compendium of international method of analysis - OIV, 2009. Method OIVMA-AS323-04B for sulfur dioxide determination Resolution Oeno, 377.

Danilewicz, J.C., 2003. Review of reaction mechanisms of oxygen and proposed intermediate reduction products in wine: Central role of iron and copper. Am. J. Enol. Vitic. 54, 73-85.

Danilewicz, J.C., 2007. Interaction of sulfur dioxide, polyphenols, and oxygen in a wine-model system: Central role of iron and copper. Am. J. Enol. Vitic. 58, 53-60.

Danilewicz, J.C., Seccombe, J.T. \& Whelan, J., 2008. Mechanism of interaction of polyphenols, oxygen, and sulphur dioxide in model wine and wine. Am. J. Enol. Vitic. 59, 128-136.

Dott, W., Heinzel, M. \& Trüper, H.G., 1976. Sulfite formation by wine yeasts. I. Relationships between growth, fermentation and sulfite formation. Arch. Microbiol. 107, 289-292.

Du Toit, W.J., 2006. The effect of oxygen on the composition and microbiology of red wine. Dissertation, Stellenbosch University, Private Bag X1, 7602 Matieland (Stellenbosch), South Africa.

Du Toit, W.J., Lisjak, K., Stander, M. \& Prevoo, D., 2007. Using LC-MSMS to assess glutathione levels in South African white grape juices and wines made with different levels of oxygen. J. Agric. Food Chem. 55, 2765-2769.

Du Toit, W.J., Marais, J., Pretorius, I.S. \& Du Toit, M., 2006. Oxygen in wine: A review. S. Afr. J. Enol. Vitic. 27, 76-94.

Fabios, M., Lopez-Toledano, A., Mayen, M., Merida, J. \& Medina, M., 2000. Phenolic compounds and browning in sherry wines subjected to oxidative and biological aging. J. Agric. Food Chem. 48, 2155-2159.

Fracassetti, D., Lawrence, N., Tredoux, A.G.J., Tirelli, A., Nieuwoudt, H.H. \& Du Toit, W.J., 2011. Quantification of glutathione, catechin and caffeic acid in grape juice and wine by a novel ultra-performance liquid chromatography method. Food Chem. 128, 1136-1142.

Godden, P., Leigh, F., Field, J., Gishen, M., Coulter, A., Valente, P., Hoj, P. \& Robinson, E., 2001. Wine bottle closures: Physical characteristics and effect on composition and sensory properties of a Semillon wine. 1. Performance up to 20 months post-bottling. Aust. J. Grape Wine Res. 7, 64-105.

Hosry, L.E., Auezova, L., Sakr, A. \& Hajj-Moussa, E., 2009. Browning susceptibility of white wine and antioxidant effect of glutathione. Intern. J. Food Sci. Techn. 44, 2459-2463.

Jolliffe, I.T., 1986. Principal component analysis. Springer-Verlag, New York.

Kilmartin, P.A., Zou, H. \& Waterhouse, A.L., 2001. A cyclic voltammetry method suitable for characterizing antioxidant properties of wine and wine phenolics. J. Agric. Food Chem. 49, 1957-1965.

Labrouche, F., Clark, A.C., Prenzler, P.D. \& Scollary, G.R., 2005. Isomeric influence on the oxidative coloration of phenolic compounds in a model white wine: Comparison of (+)-catechin and (-)-epicatechin. J. Agric. Food Chem. 53, 9993-9998.
Lavigne, V. \& Dubourdieu, D., (2004). Affinamento sulle fecce e freschezza dei vini bianchi. VigneVini 31, 58-66.

Li, H., Guo, A. \& Wang, H., 2008. Mechanisms of oxidative browning of wine. Food Chem. 108, 1-13.

Margalit, Y., 1997 ( $2^{\text {nd }}$ ed). Concepts in wine chemistry. The Wine Appreciation Guild, San Francisco.

Papadopoulou, D. \& Roussis, I.G., 2008. Inhibition of the decrease of volatile esters and terpenes during storage of a white wine and a model wine medium by glutathione and N-acetylcysteine. Intern. J. Food Sci. Techn. 43, 1053-1057.

Peng, Z., Iland, P.G., Oberholster, A., Sefton, M.A. \& Waters, E.J., 2002. Analysis of pigmented polymers in red wine by reverse phase HPLC. Aust. J. Grape Wine Res. 8, 70-75.

Ribéreau-Gayon, P., Glories, Y., Maujean, A. \& Dubourdieu, D., 2006 (2 ${ }^{\text {nd }}$ ed). Handbook of enology, vol 2. John Wiley \& Sons Ltd, Chichester.

Roussis, I.G. \& Sergianitis, S., 2008. Protection of some aroma volatiles in a model wine medium by sulphur dioxide and mixtures of glutathione with caffeic acid or gallic acid. Flav. Frag. J. 23, 35-39.

Roussis, I.G., Lambropoulos, I. \& Tzimas, P., 2007. Protection of volatiles in a wine with low sulfur dioxide by caffeic acid or glutathione. Am. J. Enol. Vitic. 58, 274-278.

Salgues, M., Cheynier, V., Gunata, Z. \& Wylde, R., 1986. Oxidation of grape juice 2-S-glutathionyl caffeoyl tartaric acid by Botrytis cinerea laccase and characterization of new substance 2,5-di-S-glutathionyl-caffeoyl tartaric acid. J. Food Sci. 51, 1191-1194.

Simpson, R.F., 1982. Factors affecting oxidative browning of white wine. Vitis 21, 233-239.

Singleton, V.L., Zaya, J., Trousdale, E. \& Salgues, M., 1984. Caftaric acid in grapes and conversion to a reaction product during processing. Vitis 23, $113-120$

Skouroumounis, G.K., Kwiatkowski, M.J., Francis, I.L., Oakey, H., Capone, D.L., Peng, Z., Duncan, B., Sefton, M.A. \& Waters, E.J., 2005. The influence of ascorbic acid on the composition, colour and flavour properties of a Riesling and a wooded Chardonnay wine during five years' storage. Aust. J. Grape Wine Res. 11, 355-368.

Sonni, F., Clark, A.C., Prenzler, P.D., Riponi, C. \& Scollary, G.R., 2011. Antioxidant action of glutathione and the ascorbic acid/glutathione pair in a model white wine. J. Agric. Food Chem. 59, 3940-3949.

Ugliano, M., Kwiatkowski, M., Vidal, S., Capone, D., Siebert, T., Dieval, J., Aagaard, O. \& Waters, E.J., 2011. Evolution of 3-mercaptohexanol, hydrogen sulfide, and methyl mercaptan during bottle storage of Sauvignon blanc wines. Effect of glutathione, copper, oxygen exposure, and closurederived oxygen. J. Agric. Food Chem. 59, 2564-2572.

Vanzo, A., Cecotti, R., Vrhovsek, U., Torres, A.M., Mattivi, F. \& Passamonti, S., 2007. The fate of trans-caftaric acid administered into the rat stomach. J. Agric. Food Chem. 55, 1604-1611.

Waterhouse, A.L., 2002. Wine phenolics. Annals of the New York Academy of Sciences 957, 21-36. 